Note: This is a pre-copy-editing, author-produced PDF of an article accepted for publication in Addiction, Research and Theory following peer review. The definitive publisher-authenticated version [McElrath $\mathrm{K}$ (2004) Drug use and drug markets in the context of political conflict: the case of Northern Ireland, Addiction, Research and Theory, 12(1) 577 - 590] is available online at

http://www.informaworld.com/smpp/title $\sim \mathrm{db}=\mathrm{all} \sim$ content $=\mathrm{g} 713637769$

\title{
Drug use and drug markets in the context of political conflict: The case of Northern Ireland
}

\author{
Karen McElrath \\ School of Sociology and Social Policy, Queen's University, Belfast BT7 1LQ, N. Ireland \\ Published in Addiction, Research and Theory (2004) 12(1) 577 - 590
}

\begin{abstract}
The focus of this article addresses drug use and drug markets in Northern Ireland against the backdrop of the most recent Irish political conflict, e.g., 1969 to the present. Between 1969 and 1999, a total of 3289 individuals had died and more than 40000 were injured as a result of the Northern Ireland political conflict. Extrapolating the data to Britain, comparable figures would reflect 111000 fatalities and over one million injured (Hayes and McAllister, 2000). This paper describes how the nature of the Northern Ireland political conflict contributed to low levels of drug use in the 1970s and 1980s. In 1994, the cessation of military operations by the Irish Republican Army (IRA) and subsequently by mainstream Loyalist organizations led to the possibility of widespread political and social change. Use of certain drugs, namely heroin, appeared to increase from the mid-1990s, although the effects of political conflict on drug use are less clear during the post-ceasefire era.
\end{abstract}

Keywords: Drug use prevalence; Political conflict; Political change; Northern Ireland

\section{Drug use in Northern Ireland, pre-1995}

A vast amount of scholarly literature has focused on illicit drug use and in many countries, this literature has a long history. A considerable amount of research has been based on samples drawn from England, Scotland and the south of Ireland and this body of research has contributed to our understanding of drug taking and drug markets in those regions. It is striking that a review of the published scholarly literature failed to locate any study of illicit drug use in Northern Ireland prior to $1990 .{ }^{1}$ The lack of research into drug use in Northern Ireland prior to 1990 was probably the result of various factors, notably the heavy research emphasis on the wider Irish political conflict. $^{2}$ For example, Whyte (1991:viii) suggested the possibility that relative to its geographic size, Northern Ireland has been perhaps the most widely researched area in the world. This research, however, has focused primarily on aspects of the political conflict so that several other topics of sociological inquiry have only recently been examined.

Self-report studies of illicit drug use have a long history, dating to at least the 1950s in the United States (Short and Nye, 1957). Self-report studies of illicit drug use in Northern Ireland were not conducted until 40 years later, i.e., during the early 1990s. A review of this literature found that several of these studies were conducted by drug service or other agencies and located within the "grey" literature. All but one of these self-report studies was restricted to a particular area or town within Northern Ireland, so that there existed no region-wide evidence concerning drug use prevalence. Authors of most of the studies reported relatively high or moderate rates of lifetime prevalence, however, much of this research suffered from serious methodological flaws, such as inappropriate sampling and measurement problems, making it difficult to ascertain the accuracy of 
conclusions. Additionally, the authors at times stated that drug use was increasing but without longitudinal or baseline data, such conclusions were inappropriate.

Of the few indicators available prior to 1990, data suggested that drug use was quite low compared to figures derived from samples in England, Scotland and the south of Ireland. With regard to the heroin market, clearly there were pockets of heroin users in the 1980s and perhaps during the previous decade also. A total of 35 persons were officially registered as "drug addicts" in 1985 and most of those persons were notified as heroin users (cited in Murray, 1994). Retrospective data collected in a qualitative study of 43 Belfast heroin users found that some heroin users had first injected themselves in Northern Ireland during the early 1980s (McElrath, 2001). Another respondent recalled the existence of a very small and close-knit group of users who resided in Belfast in the late 1960s. Thus, these bits of evidence suggest the possibility that at least some sub-cultures of heroin users resided in Northern Ireland in the decades of the 1960s to the 1980 s, but their existence as well as any difficulties that they experienced probably were masked by the wider political conflict. A semi-historical research would now be needed to uncover heroin use and the lifestyles of users during those eras.

There is little other evidence on drug taking that is available prior to 1990. Drug treatment data were not collected in a systematic fashion and methadone was not available in Northern Ireland during that time. Ethnographic research into drug use apparently had not yet been conducted. Police indicators, i.e., drug arrests and seizures of illicit drugs, generally are quite limited in terms of their ability to gauge supply and demand. Nevertheless, data reported by police during the 1980 s and early 1990s suggested extremely low levels of seized illicit drugs and very few arrests for drug offences (Murray, 1994).

Although the available data on drug taking prior to the 1990s are quite limited, it is possible that several problematic drug users resided in Northern Ireland during this time. Clearly, the heavy journalistic and research emphasis on the wider political conflict might have masked other (nonpolitical) social problems. Similarly, government officials - so consumed with "security" objectives might simply have diverted attention and resources away from other social problems. However, it is suggested here that this possibility is unlikely. Had there existed a large number of users and active drug markets, some indication during this era would have surfaced. For example, drug treatment staff would have noticed that the available treatment space was insufficient to meet the demand. Police in Northern Ireland had and continue to have some of the most extensive powers regarding searches of persons, vehicles and homes. Surely police activity and heavy surveillance of various communities would have uncovered drug activity during this time. It did not. In 1997, McElrath (2001) conducted in-depth interviews with largely Belfast heroin users. Four of the 43 respondents had initiated heroin use in the 1970s, but none had done so in Northern Ireland. One respondent initiated elsewhere in 1969 and moved to Northern Ireland in the 1970s. During the interview he was asked whether the heroin market had changed in Northern Ireland since the 1970s. He recalled that during the 1970s, he knew every user in the region. In the 1990s, however, there were far too many users to know, and that the current users belonged to a number of different heroin using sub-cultures. From his perspective, the heroin market of the 1970s and 1980 s was very small, consisting of only a few users.

If we assume then, that during the 1970s and 1980s, the drug markets in Northern Ireland were minimal and not fully developed, what explanations can be offered for the low rate of drug taking in Northern Ireland? This issue is critical because the region had close geographic proximity to other areas that were characterized by extensive drug markets and problematic drug use, e.g., Dublin, Edinburgh, Glasgow, and various parts of England. Equally important, some conditions were in place, which have been linked elsewhere to increases in the prevalence of drug use. For example, political violence can create widespread trauma. In turn, persons affected by trauma might begin to use drugs, or increase drug usage in order to cope with trauma-related anxiety or depression. For example, survey data collected from residents of New York City in the aftermath of the 11 September attacks found increases in alcohol and marijuana consumption (Vlahov et al., 
2002). In addition, respondents who suffered from Post-Traumatic Stress Disorder (PTSD) were about five times as likely as other respondents to increase their use of marijuana after the attacks.

The most recent era of Irish conflict has been characterized by extensive political violence. Hayes and McAllister (2000) documented the implications of political violence in Northern Ireland between 1969 and 1999. Those authors reported that a total of 3289 individuals had died and more than 40000 had been injured. Additionally there had been approximately 15000 explosions and more than 35000 incidents involving a firearm. As of 1998, an estimated $20 \%$ of persons in Northern Ireland had a relation who had been killed or injured, thus, thousands of persons had direct or indirect experience with political violence. Moreover, Hayes and McAllister (2000) noted that exposure to political violence differed by religious background of victims with Catholics experiencing higher levels of political violence compared to Protestants. Moreover, residing in the cities of either Belfast or Derry was significantly related to experiencing political violence.

Since 1969 and continuing on a lesser scale today, several residents, the vast majority of whom have been Catholic, have been forced to leave their homes after Loyalists ${ }^{3}$ set houses and personal belongings afire. According to some researchers, approximately 15000 families - most of them Catholic - were displaced during the period 1969-1972 (Darby and Morris, 1974). An estimated 60000 persons were forced to leave the north altogether between 1969 and 1973 (Metress, 1995). This aspect of political violence through its disruption of social networks and other effects on lifestyles can have major implications for the mental health of those displaced (Pedersen, 2002).

Some child psychologists have suggested that children in Northern Ireland who have experienced extensive sectarianism are likely to develop negative long-term effects (Bonner, 2001). Others have been more optimistic, suggesting that many children in Northern Ireland do not appear to be affected psychologically by exposure to political violence (Muldoon et al., 2000). Research that attempts to link exposure to political violence with trauma and long-term negative effects to date is somewhat unclear. For example, the effects of repeated exposure to traumatic incidents in Northern Ireland need to be addressed in greater detail. Other research has emphasized the importance of distinguishing across neighbourhoods, where the level of political violence can differ greatly (Soskolne et al., 1996). Only a few studies have compared the effects across differing levels of political violence in Northern Ireland. In one study, children residing in areas characterized by low levels of political violence and those residing in neighbourhoods with high levels of violence had similar levels of depressive symptoms (Joseph et al., 1993). Such studies, however, would benefit from a multilevel approach, which could examine both individual and structural factors and their relationship to outcomes.

If exposure to political violence has been high in Northern Ireland, particularly in some communities and neighbourhoods, and trauma is likely to follow exposure, how do people deal with trauma? Drug taking is one option. Mind-altering drugs do just that and also affect mood. Drugs can be used to cope with traumatic events in that several substances can be used to medicate, reduce anxiety or depression. Thus, why does it appear that illicit drug use did not escalate during eras of extreme political conflict? Some evidence from the 1970 s suggests that the use of tranquillisers in Northern Ireland was quite high in comparison to other regions and countries. For example, in a comparative study of several European countries, King et al. (1982) found that the rate of tranquilliser prescriptions per adult population in Northern Ireland ranked second among the list of countries studied. The use of tranquillisers has been documented by researchers who have examined other political conflicts. Soskolne et al. (1996) found that the use of tranquillisers increased in Tel-Aviv and Jerusalem during the Persian Gulf War. It is not known whether general practitioners in Northern Ireland were over prescribing these medications or whether prescription practices were consistent with the level of need. In any event, the high level of prescribing may have been linked with trauma or anxiety associated with the political conflict. Anecdotal evidence suggests that a considerable albeit free "black market" existed during the height of political conflict in the 1970s and 1980s. For example, some local residents recall that "tablets" (i.e. Valium) were shared among adult residents, largely female, within certain 
neighbourhoods. It is possible that the drug of choice or preferred drug simply differed in Northern Ireland. Tranquillisers addressed the need of at least some segments of the populace and at no cost. Additionally, little is known about the extent of alcohol use and alcohol problems in Northern Ireland during the 1970s and 1980s. Drug use has been found in virtually every culture (Weil, 1986), although we know little about why some substances emerge as preferences in one culture, but not in another.

Resilience is another factor that might explain the low levels of illicit drug taking during extreme and long-term political conflict. Trauma does not necessarily produce PTSD and its associated consequences, e.g., drug use. ${ }^{4}$ Pedersen (2002) reported findings from a review by Yehuda and McFarlane (1995) who found that approximately $80 \%$ of people who experience trauma never develop PTSD. Zarowsky and Pedersen (2000) observed that experience of political violence can actually increase "social cohesion" among the residents affected. It is possible that residents of Northern Ireland who experienced trauma as a result of political violence turned not to mindaltering illegal substances, but instead to their immediate community. Similarly, while we might expect to find an increase in referrals to mental health services as the political conflict escalated in Northern Ireland, such increases did not occur (Loughrey, 1997). The nature of how resilience occurs during periods of war and intense conflict is not altogether clear, however, Summerfield (2000) argued that war and related conflicts can create strong community bonds - protective factors that mediate against the development of mental health problems (and possibly illicit drug use).

Some research has linked drug use to poverty and "deprivation". For example, heroin use in England and in selected regions of the United States has been associated with poverty (Pearson, 1996; Pearson and Patel, 1998). In the 1970s, Belfast was said to have had the worst housing conditions in all of Europe. In 1981, unemployment among males in Northern Ireland was estimated at $19 \%$, roughly equivalent to the highest figures in England, e.g., Merseyside. Unemployment among Catholic males in Northern Ireland was 30\% whereas the rate among Protestant males was $12 \%$ (Rowthorn and Wayne, 1985). Additionally, various indicators of deprivation were noted by several authors during the 1970 s and 1980 s, particularly in Nationalist ${ }^{5}$ areas (e.g., Conroy, 1988; Rolston and Tomlinson, 1988).

If poverty and deprivation are linked with drug use, why was drug use not pervasive in Northern Ireland? Scholars have suggested the possibility that strong cohesiveness within a community can act as a buffer against the effects of deprivation on crime (Kawachi et al., 1999). A Chicago study by Sampson and colleagues (1997) attempted to measure the concept of "collective efficacy". Those authors defined the concept in terms of whether or not people were willing to assist their neighbours, the degree to which the neighbourhood was "close-knit", whether neighbours would intervene if they observed delinquent acts, and other such related items. Controlling for a number of variables, they found that greater collective efficacy was significantly related to reductions in neighbourhood violence.

Extensive community cohesiveness as well as strong informal social controls characterized several neighbourhoods in Northern Ireland during the 1970s and 1980s in particular (e.g., Leonard, 1994). These factors might have contributed to the low levels of illicit drug use in the region. Within these neighbourhoods, strong bonds and informal social control mechanisms developed as the political conflict escalated. Several residents in Nationalist areas provided either active (e.g., the provision of safe houses) or indirect support (e.g., turning a "blind eye", failing to notify the police) for the Irish Republican Army (IRA). Drug use within these areas was frowned upon for two reasons. First, drug users and persons involved in other anti-social activity, who were arrested by police at times were encouraged by police to inform - not on drug suppliers or dealers - but on Republican activity in the area of residence (Doherty, 1994; Knox, 2002). Charges against them were dropped in exchange for information. The infiltration of informants has occurred at several historical points of the Republican struggle and at times, has greatly affected the strategy and objectives of the Republican movement. Informants have and continue to be despised. Second, there was the perception that Loyalist paramilitary groups represented the 
major sources of drug supply (Cowan, 2001; Northern Ireland Affairs Committee, 1997; Sunday Life, 2001; 1992; Sunday Times, 1998). Drug users from Nationalist areas then, contributed to Loyalist earnings, which in turn could be used to purchase weapons that would ultimately be used against Catholics. Thus, drug users were perceived to be a threat to the all-important political struggle.

For several years, the police have lacked credibility in Nationalist areas (Garrett, 1999; Knox, 2002). The police were and continue to be predominantly Protestant and have been viewed as agents of the British State. They are for the most part, unwelcome in these areas. Both the Republican ${ }^{6}$ and the Loyalist groups have acted as agents of social control within their respective communities. Persons who participate in activity that violates the social order can be subjected first to a series of threats. If the activity continues, punishment, e.g., public shame, knee-capping, expulsion, can subsequently occur (Knox, 2002). The degree to which informal social control contributed to low levels of drug use is unknown, but was likely to deter at least some individuals from using drugs or engaging in low-level dealing within particular communities.

For drug markets to expand, they often require freedom of movement whereby buyers and sellers can move within and across neighbourhoods in order to engage in drug transactions. In the 1970s and 1980 s, several communities in Northern Ireland were highly segregated and movement of persons was greatly restricted. For example, in 1972, only $23 \%$ of Belfast residents lived in "mixed"” neighbourhoods, a decline from previous years (Boal et al., 1976). In both the Unionist ${ }^{8}$ and the Nationalist communities, daily activities, e.g., social lifestyles, work, tended to occur within those areas only. For example, one study found that people who traveled by bus to visit friends and relations in other neighbourhoods preferred bus stops located farther from their homes when the nearest bus stop was located in the "other" community (Boal, 1969). Whyte (1991) cited evidence from the Standing Advisory Commission on Human Rights that found that people were hesitant to work in settings that employed a disproportionate number of employees from the "other" community. Whyte also noted that individuals were hesitant to travel through neighbourhoods in which large numbers of residents were of the "other" religious background. In addition to these restrictions, people rarely left their areas for the purpose of socialising. For example, residents who frequented pubs tended to do so within their own areas or neighbourhoods. To venture elsewhere was perceived as being dangerous. Several Belfast residents, for example, recall that the city centre was virtually "empty" at night during the 1970s and 1980s. Initiation into drug use often occurs during adolescence or young adulthood. However, during this era of political conflict, young persons could be observed more carefully simply because their lifestyle activities occurred within areas where they were known by other residents. Young adults who frequented pubs were likely to meet their neighbours, older relations or other acquaintances. It is suggested here that these interactions tended to increase the likelihood that drug use and other antisocial behaviours were closely monitored by other community residents.

Studies conducted elsewhere that have addressed the relationship between religiosity, church attendance or religious background and drug use among adolescents often find an inverse relationship (Benda, 2001; Jang and Johnson, 2001; Sutherland and Shepherd, 2001), although the relationship appears to depend in part the method by which religiosity is measured (Hodge et al., 2001). Sutherland and Shepherd (2001: 456) suggested that religious youth may simply have fewer contacts with youth who engage in drug use and other risky activities, so that peer social networks also are important. Those authors also suggested that religiosity might provide individuals with a "peace of mind" which in turn decreases the need for mind-altering drugs.

Data from 1981, indicate that religious beliefs and commitment were stronger and more pervasive in both the north and the south of Ireland, compared to other European countries (Fogarty et al., 1984). This pattern of religiosity appeared to continue throughout the decade of the 1980 s and into the early 1990s (Hornsby-Smith and Whelan, 1994; Inglehart and Baker, 2000). Did high levels of religiosity contribute to low levels of drug taking during these decades? The argument is not a convincing one; while drug use remained apparently low in the North of Ireland, heroin use and injecting drug use began to surface widely in the late 1970 s and early 1980 s, and 
subsequently increased in the South of Ireland, namely Dublin (Butler, 1991), where levels of religiosity mirrored those in the North. It is therefore unlikely that religiosity can account fully for the low level of drug use in Northern Ireland prior to the 1990s.

In 1969, the number of full-time police officers with the Royal Ulster Constabulary (RUC) was approximately 3500 . The size of the force had increased to about 8500 officers by the mid-1990s. There were approximately 5500 additional full- and part-time "soldiers" in the Royal Irish Regiment (CAIN, 2003). In 1972, there were approximately 30000 members of the British Army who had been assigned to Northern Ireland and 18500 in 1994 (CAIN, 2003). The borders between North and South Ireland were closely monitored and checks on and searches of persons, property, and vehicles were commonplace under "emergency" legislation. Did these policing tactics prevent or reduce the supply of illicit drugs in Northern Ireland? Police in Northern Ireland have presented this argument and have suggested that a reduction in the size of the police force as a result of the 1994 ceasefires, contributed to the increase in the availability of illicit drugs (Northern Ireland Affairs Committee, 1997)

\section{Post-ceasefires: 1995 to 2003}

From 1995, most drug use research has focused on self-report studies of either youth or adults. For example, the Northern Ireland Crime Survey, conducted in 1998 found the following lifetime prevalence rates: cannabis (18\%), amphetamine (6\%), magic mushrooms (5\%), LSD $(5 \%)$, and MDMA (5\%). Approximately $2 \%$ or less had used cocaine, crack and heroin (Hague et al., 2000). In comparison, the British Crime Survey data collected in the same year found higher lifetime prevalence rates for cannabis (25\%), amphetamine (10\%), and cocaine (3\%). Lifetime prevalence rates for magic mushrooms, LSD, crack and heroin were approximately the same in the two regions. Use of MDMA was slightly higher in Northern Ireland compared to Britain (5\% vs. $4 \%$ ). No major substantive differences in last month prevalence were noted across the two surveys. Self-report data collected from youth aged 15 and 16 years in 1999 found that respondents residing in Northern Ireland had the highest rates for glue and solvent use and the prevalence rates for MDMA and heroin were higher among youth residing in Northern Ireland and Scotland compared to young persons residing in England and Wales (Plant and Miller, 2000).

For other drug use surveys conducted in Northern Ireland, serious methodological flaws in the study procedures prevent accurate conclusions from being drawn. For example, the Northern Ireland Omnibus Survey of 2000 focused on youth aged 16-25 years. Research staff distributed questionnaires to selected households, and asked the respondents to return the questionnaires by post (Miller and Dowds, 2002). That survey allegedly suffered from a very low response rate for the drug use items, although the response rate has not been made available publicly. Despite these drawbacks, data derived from that survey have been circulated and quoted widely. Nearly all of the survey research into drug use in Northern Ireland has been based on cross-sectional designs so that longitudinal data on drug use is seriously lacking in Northern Ireland. One exception is the Belfast Youth Study, a multi-year longitudinal study undertaken by a team of researchers housed within the Centre for Child Care Research at Queen's University. The results will shed important light on patterns of drug taking over time.

One potentially major problem with the survey data in Northern Ireland concerns the lack of research attention into respondents' perceptions of interviewer traits and survey sponsorship. For instance, research is lacking with regard to how respondents perceive the religious background of the interviewer, data collector or researcher and whether these perceptions affect response rates and valid responses to individual questions. For several years, many people in Northern Ireland have used various cues to determine the religious background of strangers and acquaintances with whom they interact (Cairns, 1980; Parker, 1993). Persons from "other" backgrounds are at times viewed with distrust. Moreover, residents in Northern Ireland have been suspicious of researchers (Bufwack, 1975) who have been perceived to be assisting with the surveillance for the British State (for a brief review, see Lee, 1995). These issues have been fuelled by the wider political conflict but are rarely mentioned in methodology sections of studies that are based on 
survey data collected in Northern Ireland. With regard to survey sponsorship, the Northern Ireland Crime Survey draws funding from the British government through the Northern Ireland Office (NIO). However, several individuals from Nationalist communities distrust the British government and the NIO. For instance, Ellison (2000) found that some Catholic youth in his target sample participated in the study only after the author provided letters stating that his study was not affiliated with the police or with the NIO. An earlier international victimization survey in which Northern Ireland was included was led by senior researcher Pat Mayhew. Another individual, Patrick Mayhew, served as the Secretary of State for Northern Ireland and was disliked by several residents in Nationalist communities. Did the similarity in names provoke distrust among some potential respondents? The degree to which the government-sponsored survey research in Northern Ireland or the perception thereof affects other potential respondents is not known and the issue is rarely discussed in public or academic forums.

Drug research in Northern Ireland has been dominated by survey methodology. Surprisingly, the first qualitative study into illicit drug use in the region did not occur until 1997 and focused on MDMA (McElrath and McEvoy, 2002; 2001a; 2001b). This study was based on in-depth interviews with 98 current and former users of MDMA. Many respondents perceived that MDMA had helped to "bridge the gap" between Protestant and Catholic youth in selected club settings. However, any improvement in relations generally disappeared on the return from club venues (McElrath and McEvoy, 2001a). The authors also noted that the sample included a disproportionate number of "heavy users". ${ }^{9}$ For example, approximately $44 \%$ of the sample had used Ecstasy on at least 100 different occasions or "hundreds" of times over the lifetime. To date, an ethnographic tradition in the area of drug research is quite limited in Northern Ireland.

\section{The heroin market}

O'Neill's 1995 case study of out-of-treatment drug users found that some respondents reported that a heroin or injecting culture in Northern Ireland had at that time, not yet surfaced in the region. Those perceptions might have been accurate. Limited public acknowledgement of heroin use appeared to enter the Northern Ireland public domain in the mid-1990s. The emergence of a "heroin problem" was probably first observed by astute community workers, users themselves and relatives of users. Official data on heroin demand, such as the Northern Ireland Register of Addicts (also known as the Addicts Index and still utilised, unlike the UK Index) and police seizures, are considered to be lagged indicators and would fail to show major increases for several months.

Beginning in 1995-1996, considerable media attention focused on what was perceived to be the growing heroin problem in Northern Ireland. Media portrayals of users describing their "heroin hell" dominated media interest on drugs in general. Much of the focus centred on Ballymena, a relatively small town of approximately 30000 residents, located some 27 miles from urban Belfast. A small-scale unpublished study conducted in 1999-2000, estimated that 235 to 398 heroin users resided in the Ballymena area (Woodhouse et al., 2000). Media estimates were considerably higher and ranged from 1000 to 1500 in Ballymena (Irish News, 2000; Yankova, 2000). Although this focus appeared to be exaggerated initially, other evidence began to surface that pointed to a growing number of problem heroin users in the small town. For example, a number of general practitioners from Ballymena began to organize in the late 1990s with the intention of determining foundations for best practice in the treatment of heroin-dependence. Their surgeries appeared to have disproportionate numbers of patients who were presenting with heroin dependence and heroin-related health issues. GPs and drug treatment centres in Ballymena (and elsewhere) were not permitted to prescribe methadone for maintenance purposes and GPs in particular voiced frustration at the lack of appropriate guidance with regard to treatment for heroin dependence. The GP-led group organised visits to specialist services in Edinburgh, Glasgow and Dublin in order to learn more about appropriate treatment for heroin-dependence. Family members of heroin users organised local support groups and one community worker subtly began to distribute new needles and syringes. These efforts were fuelled by what residents and professionals observed to be the emergence of a strong heroin market in the area. Drug policy 
initiatives were slow to respond. For example, despite early indications of an emerging heroin market in the mid-1990s, as recently as early 2000 needle exchanges had not been implemented in Ballymena or any other location in Northern Ireland. Moreover, a study conducted in 1997-1999 and based on in-depth interviews with largely Belfast heroin injectors revealed the unusual pattern of urban users traveling to Ballymena to buy heroin (McElrath, 2001). Prior to the 1990s, several users had obtained the drug from Dublin markets. The heroin market appeared to be firmly entrenched in Ballymena.

How large is the heroin problem in Northern Ireland? Recall that a total of 35 persons were notified as drug "addicts" in 1985, and that the majority of these persons were heroin users. In 1997, 78 persons appeared as registered heroin "addicts" in Northern Ireland. The number of persons notified for heroin continued to increase in the late 1990s and reached 233 in $2000 .^{10}$ It is suggested here, however, that there was indeed an increase in heroin use beginning in approximately the mid-1990s. A three-sample capture-recapture study estimated that there were approximately 828 problem heroin users (95\% Cl 695 to 1018) in Northern Ireland during the 12month period, 1 November 2000 to 31 October 2001 (McElrath, 2002). Clearly, a market for heroin had developed.

As described above, methadone and other forms of substitute prescribing, e.g., Subutex, were generally not available for maintenance purposes although a small pilot programme was introduced in the city of Bangor, located southeast of Belfast. Substitute prescribing for maintenance purposes was for the most part limited to DFs and benzodiazepines; several years earlier, the (UK) Department of Health's guidelines on methadone and other forms of substitute prescribing had been virtually ignored in Northern Ireland. In place of the UK guidelines, the local drug policy makers developed their own, and adopted a practice of advocating treatment without methadone. In 2002, the Department of Health, Social Services and Public Safety (DHSSPS) commissioned an external review of the international evidence on substitute prescribing for heroin dependence (McElrath, 2003). That report included several recommendations, including the immediate need for methadone and Subutex maintenance as treatment options. Most of the recommendations were supported by the DHSSPS and the implementation details were in the planning stages during late 2003. The change in policy might have been influenced by growing pressure from various staff in drug services. Additionally, some key personnel within the Department appeared to be more open to the possibility of the availability of substitute prescribing. The degree to which the implementation of substitute prescribing will change the heroin market in Northern Ireland is not known but will be closely monitored.

\section{Conclusion}

The extent of drug use as well as the development of drug markets in Northern Ireland have differed in comparison to other geographic regions of close proximity. There is no real evidence that suggests that illicit drug taking was widespread during the 1970s and 1980s. Rather, Northern Ireland appeared to be a region of low prevalence. This article explored possible explanations for the low level of illicit drug use during these decades. Although political violence was extensive and collective trauma affected large numbers of the population, other effects of the political conflict appeared to have contributed to low levels of drug use. In particular, the nature of the political conflict helped create strong social bonds within neighbourhoods, reduced geographic mobility, and contributed to the development of informal social controls. It is also possible that other substances, e.g., tranquillisers, were readily available, were inexpensive and met the needs of certain individuals.

The evidence to date suggests that changes in drug use occurred at some stage after the 1994 ceasefires. Clearly, several indicators suggest that the heroin market has expanded greatly since the mid-1990s. A study conducted in the late 1990s of MDMA use in Northern Ireland found a disproportionate number of "heavy users" of the drug (McElrath and McEvoy, 2002). The first allIreland drug prevalence survey found a slightly higher lifetime prevalence rate of MDMA in the North of Ireland (6\%) compared to the South (4\%) (MORI MRC, 2003). We are less clear about 
how these changes relate to the wider political conflict. The nature of political violence has changed and the extent of political violence has also declined, but still affects many residents in some areas of Northern Ireland. Moreover, little is known about whether or not social cohesion within neighbourhoods has been eroded since the 1990s. At present, people appear to have fewer restrictions placed upon their geographic mobility. In one study, several young adults recalled their first visits to city centre clubs after the ceasefires had been announced in 1994 (McElrath and McEvoy, 2001a). A number of respondents in that study reported that their first interactions with persons from the "other" community coincided with the development of the club scene in "neutral" areas after the 1994 ceasefires.

Some officials in Northern Ireland continue to emphasize differences in patterns of drug use in Northern Ireland and neighbouring regions. Moreover, that perceived differentness has been used to justify conservative drug policies. In many ways, there are now strong similarities between Northern Ireland and elsewhere. For example, sub-cultures of young heroin users emerged in non-urban areas within Northern Ireland during the mid-1990s. Similar reports have been documented in England (Parker et al., 1998; Egginton and Parker, 2000). It will be interesting to note whether these sub-cultures develop further. Measures of lifetime prevalence appear to be comparable (e.g., Hague, Willis and Power, 2000; Plant and Miller, 2000). For the first time, drug taking in Northern Ireland may begin to mirror that which occurs in neighbouring regions.

\section{Notes}

1 One notable exception focused on the apparently widespread use of Ether during the $1800 \mathrm{~s}$ in the small village of Draperstown, County Derry.

2 Prior to the 1990s, very few if any scholars had research expertise in the area of illicit drug use.

3 Loyalists are individuals who seek to maintain the linkage with Britain and believe that violence is justified in pursuit of this goal. In general, most Loyalists come from Protestant backgrounds.

4 Summerfield (1996) noted that confounding factors, particularly in studies that examine longterm effects of trauma, need to be better controlled.

5 Nationalists seek a united Ireland - one free of British involvement. Nationalists come primarily from Catholic backgrounds and are more likely to identify themselves as Irish rather than British.

6 Republicans support the idea of a united Ireland, free of British involvement. Armed struggle in pursuit of this goal is perceived to be justified among Republicans. The Irish Republican Army most likely represents the largest Republican organisation in Northern Ireland.

7 In Northern Ireland the term "mixed" in this sense refers to neighbourhoods that include both Protestant and Catholic residents. The term also is used to describe a marriage between a Protestant and Catholic.

8 Unionists are primarily from Protestant backgrounds and seek to maintain the ties with Britain.

9 The authors acknowledged the subjectivity of this term.

10 We are less clear about whether this change represents an increase in the number of heroin users who came to the attention of general practitioners and drug treatment staff, or whether this difference reflects changes in the degree to which users sought help, or the degree to which GPs and treatment staff complied with regulations about reporting. For example, the nowdefunct United Kingdom Addicts Index of which the Northern Ireland was once a part, tended to underestimate the number of persons addicted to heroin (Mott, 1994). 


\section{References}

1. Benda, B. B. (2001) Religiosity and church attendance: the effects on use of "hard drugs" controlling for sociodemographic and theoretical factors. International Journal for the Psychology of Religion 10 , pp. 241-258.

2. Boal, F. W. (1969) Territoriality on the Shankill-Falls Divide, Belfast. Irish Geography 6 , pp. 30 50.

3. Boal, F. W., Murray, R. C. and Poole, M. A. (1976) Belfast: The urban encapsulation of a national conflict. Urban Ethnic Conflict: A Comparison Perspective; Institute for Research in Social Science p. 77. Chapel HillNorth Carolina - In: Clarke, S.C. and Obler, H.L. (Eds.)

4. Bonner, A. (2001) Children could be left traumatized by events at school warns psychologist. Irish News

5. Bufwack, M. A. (1975) Village without Violence: An Examination of a Northern Irish Village; Washington University St. LouisMO - Unpublished doctoral dissertation

6. Butler, S. (1991) Drug problems and drug policies in Ireland: a quarter of a century reviewed. Administration 39 , pp. 210-233.

7. (2003) Background information on Northern Ireland society - Security and Defence. Available on the World Wide Web at: http://cain.ulst.ac.uk/ni/security.htm

8. Cairns, E. (1980) The development of ethnic discrimination in children in Northern Ireland. $A$ Society under Stress: Children and Young People in Northern Ireland; Open Books p. 115. Shepton Mallet — In: Harbison, J. and Harbison, J. (Eds)

9. Conroy, J. (1988) War as a Way of Life: A Belfast Diary; Heinemann London

10. Cowan, R. (2001) Loyalists claim drugs shooting. The Guardian - 4 December

11. Darby, J. and Morris, G. (1974) Intimidation in Housing; Northern Ireland Community Relations Commission Belfast

12. Doherty, F. (1994) IRA acts quickly to quash white lady drug threat. Sunday Tribune - 8 May: 10

13. Egginton, R. and Parker, H. (2000) Hidden heroin users: Young people's unchallenged journeys to problematic drug use; DrugScope London

14. Ellison, G. (2000) Reflecting all shades of opinion: public attitudinal surveys and the construction of police legitimacy in Northern Ireland. British Journal of Criminology 40 , pp. 88110.

15. Fogarty, M. P. (1984) Irish Values and Attitudes: The Irish Report of the European Value Systems Study; Dominican Dublin

16. Garrett, P. M. (1999) The pretence of normality: intra-family violence and the response of state agencies in Northern Ireland. Critical Social Policy 19, pp. 31-55.

17. Hague, L., Willis, M. and Power, M. (2000) Experience of Drug Misuse: Findings from the 1998 Northern Ireland Crime Survey; Northern Ireland Office Belfast — Research and Statistical Bulletin 4/2000, July

18. Hayes, B. C. and McAllister, I. (2000) Sowing dragon's teeth: Public support for political violence and paramilitarism in Northern Ireland. - Paper presented for the meetings of the United Kingdom Political Studies Association, London School of Economics, April

19. Hodge, D. R., Cardenas, P. and Montoya, H. (2001) Substance use: spirituality and religious participation as protective factors among rural youths. Social Work Research 25 , pp. 153161.

20. Hornsby-Smith, M. P. and Whelan, C. T. (1994) Religion and moral values. Values and Social Change in Ireland; Gill and Macmillan p. 7. Dublin - In: Whelan, C.T. (Ed.)

21. Inglehart, R. and Baker, W. E. (2000) Modernization, cultural change, and the persistence of traditional values. American Sociological Review 65 , pp. 19-51.

22. (2000) Addict toll rising in capital of heroin use. - 17 February. Available on the World Wide Web at: http://www.irishnews.com

23. Jang, S. J. and Johnson, B. R. (2001) Neighbourhood disorder, individual religiosity and adolescent use of illicit drugs: a test of multilevel hypotheses. Criminology 39 , pp. 109-141. 
24. Joseph, S., Cairns, E. and McCollam, P. (1993) Political violence, coping and depressive symptomatology in Northern Ireland children. Personality and Individual Differences 15 , pp. 471-473.

25. Kawachi, I., Kennedy, B. P. and Wilkinson, R. G. (1999) Crime: social disorganization and relative deprivation. Social Science and Medicine 48 , pp. 719-731.

26. King, D. J., Griffith, K., Reilly, P. M. and Merrett, J. D. (1982) Psycotropic drug use in Northern Ireland 1966-1980: prescribing trends, intra- and interregional comparisons and relationships to demographic and socioeconomic variables. Psychological Medicine 12 , pp. 819-833.

27. Knox, C. (2002) See no evil, hear no evil: Insidious paramilitary violence in Northern Ireland. British Journal of Criminology 42 , pp. 164-185.

28. Lee, R. M. (1995) Dangerous Fieldwork; Sage Thousand OaksCA

29. Leonard, M. (1994) Informal Economic Activity in Belfast; Avebury Aldershot

30. Loughrey, G. (1997) Civil violence. Psychological Trauma: A Developmental Approach; Gaskell p. 156. London — In: Black, D., Newman, M., Harris Hendricks, J. and Mezey, G. (Eds.)

31. McElrath, K. (2003) Review of Research on Substitute Prescribing for Opiate Dependence and Implications for N. Ireland; Department of Health, Social Services and Public Safety Belfast

32. McElrath, K. (2002) Prevalence of Problem Heroin Use in Northern Ireland; Department of Health, Social Services and Public Safety Belfast

33. McElrath, K. (2001) Heroin Use in Northern Ireland: A Qualitative Study into Heroin Users' Lifestyles, Experiences, and Risk Behaviours; Department of Health, Social Services and Public Safety Belfast

35. McElrath, K. and McEvoy, K. (2001a) Fact, fiction and function: mythmaking and the social construction of Ecstasy use. Substance Use and Misuse 36 , pp. 1-22.

36. McElrath, K. and McEvoy, K. (2001b) Heroin as evil: ecstasy users' perceptions about heroin. Drugs: Education, Prevention and Policy 8 , pp. 177-189.

37. Metress, S. P. (1995) Outlines in Irish History: Eight Hundred Years of Struggle; Connolly Books Detroit

38. Miller, R. and Dowds, L. (2002) Drug and Alcohol Use among Young People: A Secondary Analysis of Drug and Alcohol Use Surveys; Department of Health, Social Services and Public Safety Belfast

39. (2003) Drug Use in Ireland and Northern Ireland: First Results from the 2002/2003 Drug Prevalence Survey - A Summary of the Methodology; Drug and Alcohol Information and Research Unit; National Advisory Committee on Drugs Belfast

40. Mott, J. (1994) Notification and the Home Office. Heroin Addiction and Drug Policy: The British System; Oxford University Press p. 270. Oxford - In: Strang, J. and Gossop, M. (Eds)

41. Muldoon, O. T., Trew, K. and Kilpatrick, R. (2000) The legacy of the troubles on the young people's psychological and social development and their school life. Youth and Society 32 , pp. 6-28.

42. Murray, M. (1994) Use of illegal drugs in Northern Ireland. Heroin Addiction and Drug Policy: The British System; Oxford University Press p. 134. Oxford - In: Strang, J. and Gossop, M. (Eds)

43. (1997) Illicit Drug Use in Northern Ireland; House of Commons London

44. Parker, H., Bury, C. and Egginton, R. (1998) New heroin outbreaks amongst young people in England and Wales; Home Office London - Crime Detection and Prevention Series, Paper 92

45. Parker, T. (1993) May the Lord in His Mercy be Kind to Belfast; Henry Holt and Company New York

46. Pearson, G. (1996) Drugs and deprivation. Journal of the Royal Society of Health 116 , pp. 113-116. 
48. Pedersen, D. (2002) Political violence, ethnic conflict, and contemporary wars: broad implications for health and social well-being. Social Science and Medicine 55 , pp. 175-190.

49. Plant, M. and Miller, P. (2000) Drug use has declined among teenagers in United Kingdom. British Medical Journal 320

50. Rolston, B. and Tomlinson, M. (1988) Unemployment in West Belfast: The Obair Report; Beyond the Pale Publications Belfast

51. Rowthorn, B. and Wayne, N. (1985) Northern Ireland: The Political Economy of Conflict; Polity Cambridge

52. Sampson, R. J., Raudenbush, S. W. and Earls, F. (1997) Neighbourhood and violent crime: a multilevel study of collective efficacy. Science 277 , pp. 918-924.

53. Short, J. F. and Nye, F. I. (1957) Reported behavior as a criterion of deviant behavior. Social Problems 5 , pp. 207-213.

54. Soskolne, V., Baras, M., Palti, H. and Epstein, L. (1996) Exposure to missile attacks: the impact of the Persian Gulf War on physical health, health behaviours and psychological distress in high and low risk areas in Israel. Social Science and Medicine 42 , pp. 1039-1047.

55. Summerfield, D. (2000) War and mental health: a brief overview. British Medical Journal 321 , pp. 232-235.

56. Summerfield, D. (1996) The psychological legacy of war and atrocity: the question of long term and transgenerational effects and the need for a broad view. Journal of Nervous and Mental Disease 184 , pp. 375-377.

57. (2001) UDA's drugs empire exposed. - 26 August

58. (1992) Drug dealers prompt UVF purge. - 1 March

59. (1998) Scots gang join loyalist drugs for arms network. - 18 January

60. Sutherland, I. and Shepherd, J. P. (2001) Social dimensions of adolescent substance use. Addiction 96 , pp. 445-458.

62. Weil, A. (1986) Why people take drugs. The Natural Mind, A; Houghton Mifflin p. 17. MA Weil (au.)

63. Whyte, J. (1991) Interpreting Northern Ireland; Clarendon Paperbacks Oxford

64. Woodhouse, L., McLaughlin, D., Mulhall, P. and Patterson, M. (2000) Heroin Needs Assessment; Homefirst Community Trust, Community Addiction Service Ballymena

65. Yankova, S. (2000) Agencies to unite in war on heroin. Irish News - 27 October. Available on the World Wide Web at: http://www.irishnews.com

66. Yehuda, R. and McFarlane, A. C. (1995) Conflict between current knowledge about posttraumatic stress disorder and its original conceptual basis. American Journal of Psychiatry 152 , pp. 1705-1713.

67. Zarowsky, C. and Pedersen, D. (2000) Rethinking trauma in a transnational world (Editorial). Transcultural Psychiatry 37 , pp. 291-293. 